\begin{tabular}{|c|c|c|}
\hline \multirow{3}{*}{$\begin{array}{l}\text { Case Reports in } \\
\text { Gastroenterology }\end{array}$} & \multirow{2}{*}{\multicolumn{2}{|c|}{ Case Rep Gastroenterol 2013;7:404-408 }} \\
\hline & & \\
\hline & $\begin{array}{l}\text { DOI: 10.1159/000355347 } \\
\text { Publisnea onine: september 10, } 2013\end{array}$ & $\begin{array}{l}\text { (c) } 2013 \text { S. Karger AG, Basel } \\
1662-0631 / 13 / 0073-0404 \$ 38.00 / 0 \\
\text { www.karger.com/crg }\end{array}$ \\
\hline & \multicolumn{2}{|c|}{$\begin{array}{l}\text { This is an Open Access article licensed under the terms of the Creative Common } \\
\text { Attribution-NonCommercial } 3.0 \text { Unported license (CC BY-NC) (www.karger.com/OA } \\
\text { license), applicable to the online version of the article only. Distribution permitted for non } \\
\text { commercial purposes only. }\end{array}$} \\
\hline
\end{tabular}

\title{
Infected Walled-Off Pancreatic Necrosis following EUS-Guided Drainage Successfully Treated Using Multiple Stents in Different Sites Technique
}

\author{
Varayu Prachayakul ${ }^{\mathrm{a}} \quad$ Pojamana Phisalprapab $^{\mathrm{b}}$ Pitulak Aswakul $^{\mathrm{c}}$ \\ ${ }^{a}$ Siriraj GI Endoscopy Center, Siriraj Hospital, Division of Gastroenterology, and ${ }^{b}$ Siriraj \\ Hospital, Division of Ambulatory Medicine, Department of Medicine, Faculty of Medicine, \\ Mahidol University, and 'Liver and Digestive Institute, Samitivej Sukhumvit Hospital, \\ Bangkok, Thailand
}

\section{Key Words}

Walled-off pancreatic necrosis $\cdot$ Infection $\cdot$ EUS-guided drainage $\cdot$ Multiple stenting

\begin{abstract}
Walled-off pancreatic necrosis (WOPN) is one of the most life-threatening complications of acute severe pancreatitis. Regarding its high mortality and morbidity without appropriate treatment, the drainage procedure is still the mainstay of the treatment for this condition. There are multiple drainage options for this event. To date, endoscopic drainage alone has not been adequate for this condition, while surgical drainage has been reported to have a high morbidity. Endoscopic drainage with pancreatic necrosectomy is the most effective and safe method, while endoscopic drainage with aggressive lavage is another acceptable treatment option. The procedural details have been described elsewhere in many studies. In this report, we describe an alternative technique of drainage by endoscopy alone, without aggressive lavage procedure, that yielded an acceptable outcome with an easier procedure.
\end{abstract}

(c) 2013 S. Karger AG, Basel

\section{Introduction}

Walled-off pancreatic necrosis (WOPN) is an uncommon complication of acute severe pancreatitis that often leads to clinical deterioration of the patient and is associated with a very high mortality [1]. The differentiation between WOPN and pancreatic pseudocyst is

Varayu Prachayakul

Siriraj GI Endoscopy Center, Siriraj Hospital, Division of Gastroenterology

Department of Medicine, Faculty of Medicine, Mahidol University

Bangkok 10700 (Thailand)

E-Mail kaiyjr@gmail.com 
Prachayakul et al.: Infected Walled-Off Pancreatic Necrosis following EUS-Guided Drainage Successfully Treated Using Multiple Stents in Different Sites Technique

based on the clinical course and radiographic findings, which show solid or necrotic material in the collection that is more distinct by magnetic resonance imaging (MRI) than by computed tomography (CT). The indications for drainage of WOPN are infection, obstruction of adjacent organs, rapidly increasing size or worsening pain. This condition has traditionally been managed surgically, with interventions by open and laparoscopic techniques. Both open surgical and laparoscopic drainage have reported success rates as high as $85-90 \%$ with complication rates of $19-92 \%$ [2].

Recently, there have been many reports regarding the high success rate of endoscopic drainage and endoscopic necrosectomy of WOPN. The results were also impressive in terms of lower complication rates compared to surgical intervention [3]. A study by Ang et al. [4] concluded that combined modality therapy (percutaneous and endoscopic drainage) provided a more effective and safer management when compared to standard percutaneous drainage alone. There have also been some studies indicating that WOPN might require multiple large bore catheters with aggressive irrigation and regular follow-up CT scanning [5]. However, the former idea of leaving the stent in place permanently in case of a disconnected pancreatic duct might have to be re-considered because of the risk of complications related to stent migration [6]. This case report features another option for WOPN drainage using multiple sites and larger bore catheters without irrigation, which might be possible in certain patients whose necrotic tissue is not too difficult to remove.

\section{Case Report}

We experienced the case of a 40-year-old female who was referred and diagnosed with a WOPN sized $13 \times 9 \times 7.4 \mathrm{~cm}$ that developed 2 weeks after an episode of acute severe pancreatitis. She was initially admitted due to acute severe epigastric pain. Her blood workup showed leukocytosis $2.73 \times 10^{3} / \mu$ l (reference range $4.0-11.0 \times 10^{3} / \mu$ ) with $91 \%$ neutrophils (reference range 40-74\%) and serum amylase 1,309 U/l (reference range 0-220 $\mathrm{U} / \mathrm{l}$ ); liver chemistry showed total bilirubin $1.9 \mathrm{mg} / \mathrm{dl}$ (reference range $0.3-1.2 \mathrm{mg} / \mathrm{dl}$ ), direct bilirubin $0.5 \mathrm{mg} / \mathrm{dl}$ (reference range $0.0-0.5 \mathrm{mg} / \mathrm{dl}$ ), AST $126 \mathrm{U} / \mathrm{l}$ (reference range 0-40 U/l), ALT $343 \mathrm{U} / \mathrm{l}$ (reference range 0-40 U/l) and alkaline phosphatase $104 \mathrm{U} / \mathrm{l}$ (reference range 32-92 U/l). She underwent endoscopic retrograde cholangiopancreatography which showed only common bile duct sludge. She did not need intensive care but developed high-grade fever with abdominal pain 14 days after admission. A CT scan showed pancreatic necrosis with fluid collection at the pancreatic body. She had high-grade fever even after intravenous antibiotics for another 7 days. She underwent EUS-guided drainage with a $10 \mathrm{Fr} \times 7 \mathrm{~cm}$ double pigtail stent, and prophylactic antibiotics were prescribed for 7 days.

However, she was re-admitted 1 week later because of severe abdominal pain and sepsis. A CT scan of the upper abdomen showed enlargement of the pancreatic collection to $15 \times 7 \times$ $14.5 \mathrm{~cm}$ with increased enhancement of the rim, septation and some air inside (fig. 1). She was scheduled for repeat EUS-guided drainage of the infected WOPN. The procedure was performed with the patient in the left lateral decubitus position using a curvilinear echoscope (GF UC-140P, Olympus, Tokyo, Japan). Endoview showed a partially clogged stent (fig. 2) and echoview showed a large collection with turbid content and some air inside (fig. 3). We punctured the abscess using a 19-gauge needle (EchoTip ${ }^{\circledR}$ Ultra, Cook Ireland, Limerick, Ireland) at a different site under EUS guidance. The aspirated fluid was noted grossly to be purulent and was sent for culture. After contrast injection, 8.5 and $10 \mathrm{Fr}$ tapered tip Teflon catheters were used for dilatation, and a $10 \mathrm{Fr} \times 7 \mathrm{~cm}$ double pigtail stent was subsequently 
Prachayakul et al.: Infected Walled-Off Pancreatic Necrosis following EUS-Guided Drainage Successfully Treated Using Multiple Stents in Different Sites Technique

inserted. Since the collection was multiseptated with thick and turbid pus, we decided to place two additional stents into the abscess for better drainage via a different puncture site using the same technique (fig. 4). The patient received an extended course of intravenous antibiotics and was discharged after 33 days of hospitalization without complications. A follow-up MRI 6 weeks later showed only a small pancreatic fluid collection (fig. 5).

\section{Discussion}

Infected WOPN following EUS-guided drainage is an unusual complication that can occur even after antibiotic prophylaxis. The pitfall in this particular case was insertion of too small a stent, which resulted in inadequate drainage and promoted infection. This complication can be treated by an endoscopic approach using insertion of multiple stents instead of proceeding directly to surgery. Varadarajulu et al. [6] described techniques of transmural drainage of WOPN using EUS guidance and multiple catheter insertion through the same puncture site, including insertion of a nasocystic tube for irrigation afterwards. Here, we have presented the alternative technique of placing $10 \mathrm{Fr}$ stents via different puncture sites and without aggressive irrigation, rather than putting multiple stents into the same puncture site followed by aggressive irrigation, which was previously reported, but which is more difficult. Regarding the study of Papachristou et al. [7] WOPN $>15 \mathrm{~cm}$ was one of the factors associated with failure of endoscopic therapy, thus surgery or combination with percutaneous drainage were recommended. Interestingly, this technique might be another treatment option for large WOPN such as in the present case. We propose that in selected cases, the technique presented here would be easier to perform and could reduce the difficulty of irrigation when compared to the techniques described elsewhere. Furthermore, the technique of using multiple large bore/multi-site stents might provide better drainage than the conventional endoscopic technique. However, in order to avoid a suboptimal endoscopic approach to WOPN, this method must be reserved for patients with less necrotic tissue and debris, and imaging studies and the patient's clinical well-being must be closely followed.

\section{Author Contributions}

V. Prachayakul developed the concept; V. Prachayakul, P. Aswakul and P. Phisalprapa contributed to the acquisition of data; V. Prachayakul and P. Aswakul wrote the paper and revised it for important intellectual content.

\section{References}

1 Ahlawat SK, Charabaty-Pishvaian A, Jackson PG, Haddad NG: Single-step EUS-guided pancreatic pseudocyst drainage using a large channel linear array echoendoscope and cystotome: results in 11 patients. JOP 2006;7:616-624.

2 Sadik R, Kalaitzakis E, Thune A, Hansen J, Jönson C: EUS-guided drainage is more successful in pancreatic pseudocysts compared with abscesses. World J Gastroenterol 2011;17:499-505.

-3 Yasuda I, Iwata K, Mukai T, Iwashita T, Moriwaki H: EUS-guided pancreatic pseudocyst drainage. Dig Endosc 2009;21:s82-s86.

-4 Ang TL, Teo EK, Fock KM: EUS-guided drainage of infected pancreatic pseudocyst: use of a 10F Soehendra dilator to facilitate a double-wire technique for initial transgastric access (with videos). Gastrointest Endosc 2008;68:192-194. 
Prachayakul et al.: Infected Walled-Off Pancreatic Necrosis following EUS-Guided Drainage Successfully Treated Using Multiple Stents in Different Sites Technique

5 Takahashi N, Papachristou GI, Schmit GD, Chahal P, LeRoy AJ, Sarr MG, Vege SS, Mandrekar JN, Baron TH: CT findings of walled-off pancreatic necrosis (WOPN): differentiation from pseudocyst and prediction of outcome after endoscopic therapy. Eur Radiol 2008;18:2522-2529.

-6 Varadarajulu S, Phadnis MA, Christein JD, Wilcox CM: Multiple transluminal gateway technique for EUSguided drainage of symptomatic walled-off pancreatic necrosis. Gastrointest Endosc 2011;74:74-80.

7 Papachristou GI, Takahashi N, Chahal P, Sarr MG, Baron TH: Peroral endoscopic drainage/debridement of walled-off pancreatic necrosis. Ann Surg 2007;245:943-951.

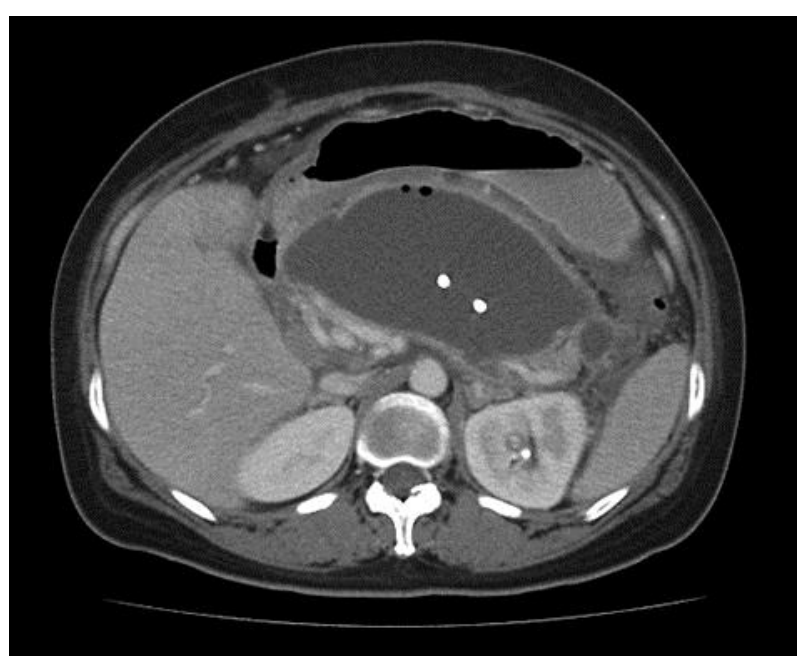

Fig. 1. CT scan showing the stent in the enlarged cyst.

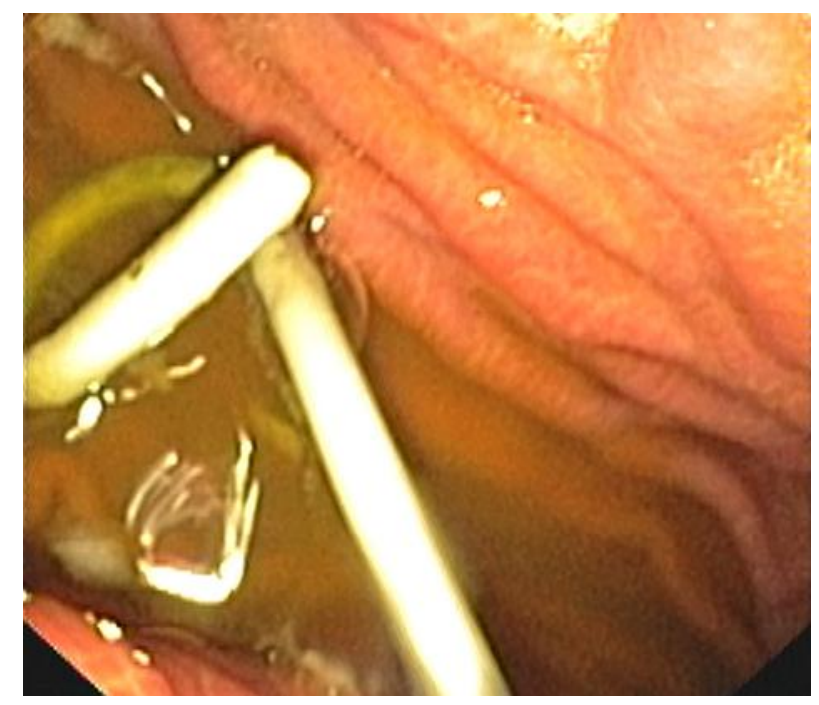

Fig. 2. A partially clogged stent. 
Prachayakul et al.: Infected Walled-Off Pancreatic Necrosis following EUS-Guided Drainage Successfully Treated Using Multiple Stents in Different Sites Technique

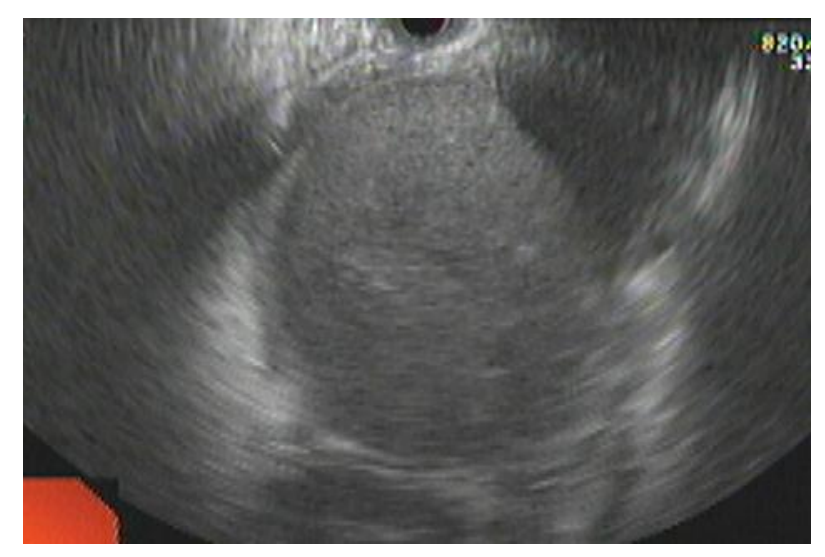

Fig. 3. Echoview showing turbid fluid with some air noted.

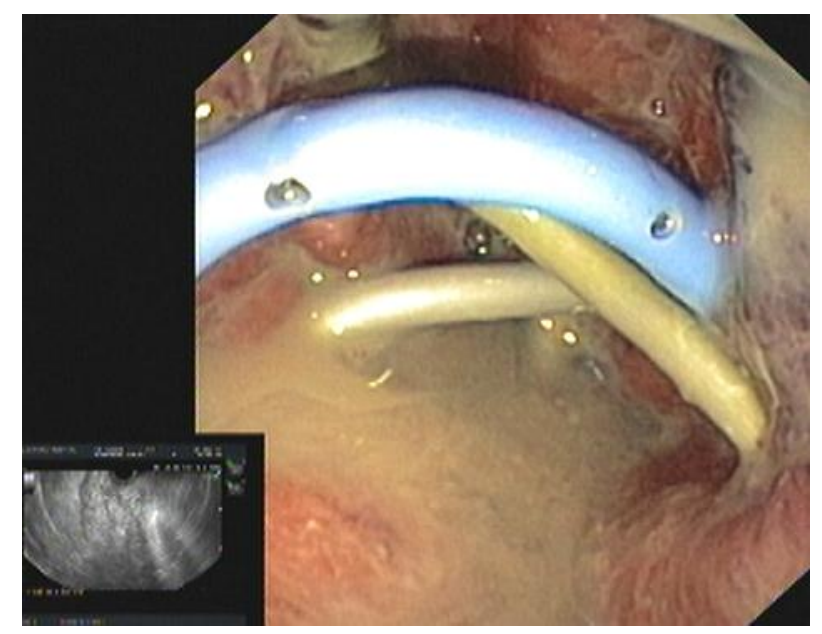

Fig. 4. Endoscopic view of stents. Purulent drainage is also seen.

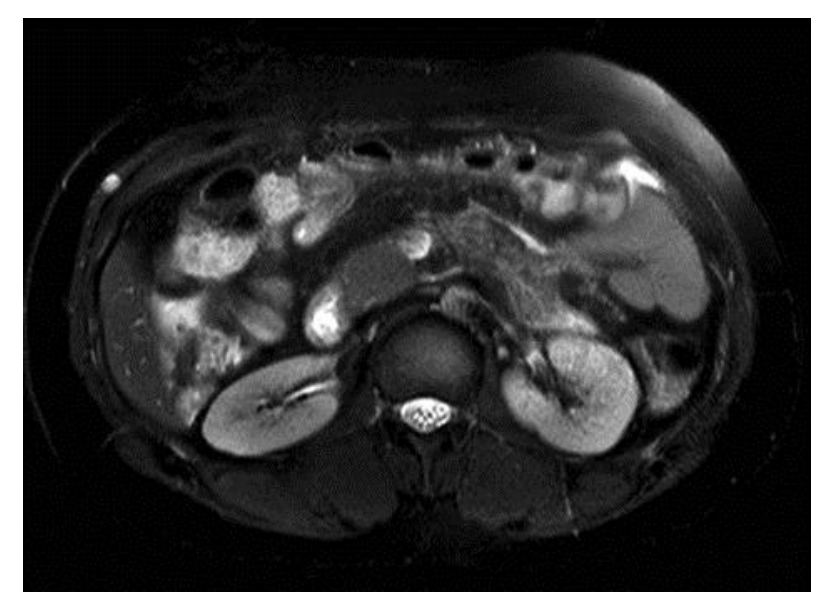

Fig. 5. Follow-up MRI showing only small residual collection. 